\title{
Fetal and Maternal Corticosterone and Corticosteroid Binding Globulin in the Diabetic Rat Gestation
}

\author{
IRA H. GEWOLB AND JOSEPH B. WARSHAW \\ Department of Pediatrics, Division of Neonatology, Albert Einstein College of Medicine, Bronx, New York 10461 \\ and Department of Pediatrics, University of Texas, Southwestern Medical School, Dallas, Texas 75235
}

\begin{abstract}
Delayed fetal lung development is a feature of the diabetic pregnancy. Since fetal glucocorticoids are important in the regulation of lung maturation, we measured corticosterone and corticosteroid-binding globulin binding capacity in streptozotocin-diabetic pregnant rats and their fetuses. Previous studies have demonstrated delayed fetal lung maturation in this animal model. In control fetuses, total corticosterone concentration increased through day 20 of gestation, then declined until day 22 (term). The unbound steroid, which accounted for 5-10\% of the total, increased approximately 3 -fold from day 18 to term. Corticosteroid-binding globulin binding capacity peaked on day 19 after which it decreased. Maternal total and unbound corticosterone levels and corticosteroid-binding globulin binding capacity remained relatively constant throughout the final week of normal gestation. When compared to controls, fetuses from diabetic pregnancies had significantly lower total corticosterone from day 19 through 22. Corticosteroid-binding globulin binding capacity was also significantly decreased in these fetuses for the last 4 days of gestation. Similar differences were noted in maternal samples. However, no significant differences in unbound, biologically active, corticosterone were seen when diabetic and control groups were compared. Thus, delayed fetal lung maturation observed in fetuses of streptozotocindiabetic rats is associated with a decrease in total circulating corticosteroid levels late in gestation. However, since unbound corticosteroid levels were similar in fetuses of control and diabetic animals, it is likely that other mechanisms may be responsible for the observed delay in lung development in fetuses of diabetic pregnancies. (Pediatr Res 20: 155-160, 1986)
\end{abstract}

\section{Abbreviations}

CBG, corticosteroid-binding globulin

Infants of diabetic mothers have a higher incidence of the respiratory distress syndrome than do infants of uncomplicated pregnancies (1). A perturbation or delay in the normal process of pulmonary maturation has also been demonstrated in a number of animal models of the diabetic gestation (2-6). However,

Received April 2, 1985: accepted September 25, 1985.

Reprint requests Ira H. Gewolb, M.D., Albert Einstein College of Medicine, Department of Pediatrics/Division of Nconatology, Jacobi 810, Bronx, NY 10461.

Supported by Biomedical Research Support Grant 613-4708 and by a GrantIn-Aid from the New York Lung Association (I.H.G.), and by NIH Grant HL30119 (J.B.W.). (I.H.G.) is the recipient of a Research Career Development Award from the Juvenile Diabetes Foundation International. at present, the precise mechanism responsible for this developmental delay is not known.

Endogenous glucocorticoids appear to have a physiologic role in the control of lung differentiation in the normally developing fetus (reviewed in Reference 7). It is well known that exogenous glucocorticoid administration can accelerate fetal lung maturation (reviewed in Reference 8). Previous studies of adrenal function and glucocorticoid levels in fetuses of diabetic pregnancies have yielded conflicting results. Early investigations of human diabetic pregnancies found either no change $(9,10)$ or increases $(11,12)$ in fetal or neonatal adrenal function and steroid levels in infants of diabetic pregnancies. In contrast, however, there is decreased amniotic fluid cortisol in human diabetic pregnancies $(13,14)$. Furthermore, recent studies with alloxan-diabetic rabbit (15) and streptozotocin-diabetic rat (16) have demonstrated decreased total glucocorticoid concentration in fetal plasma. However, none of these studies has measured the unbound, biologically active, steroid fraction in maternal and fetal plasma.

The present study was therefore designed to measure unbound and total corticosteroid levels in streptozotocin-diabetic rats and their fetuses, in order to investigate whether the delay in fetal lung maturation previously noted in this model $(2,3)$ can be accounted for by changes in circulating corticosteroid levels. CBG binding capacity was also assayed, since differences in binding capacity could affect the ratio of bound to unbound steroid.

\section{MATERIALS AND METHODS}

Animal model. Diabetes was induced in nonpregnant female Sprague-Dawley rats (Charles River Breeding Laboratories, Boston, MA) by intravenous injection of streptozotocin $(40 \mathrm{mg} / \mathrm{kg})$ as previously described (2). The intravenous injection of this dose of streptozotocin reliably resulted in manifest diabetes, with a mean blood sugar of $498 \pm 11$ (range 300-600 mg/100 ml) versus a mean of $104 \pm 2$ for control animals (2). Fetuses were also hyperglycemic, with mean plasma glucose levels of $355 \pm$ 10 versus $51 \pm 4$ for controls; in this system, however, fetuses were not hyperinsulinemic (mean plasma insulin $=75 \pm 8 \mu$ units $/ \mathrm{ml}$ versus $83 \pm 9$ for controls) (2), in keeping with observations by other investigators (17-19). After 5 days [to negate any possible direct effect of streptozotocin, which is cleared from the circulation in about $6 \mathrm{~h}(20)]$ rats were bred with normal males until successful mating occurred. Pregnant animals were then caged individually until time of decapitation. A 16:8 h light:dark cycle was in effect. Handling was kept to a minimum. All animals were killed between 0900 and $1100 \mathrm{~h}$ to minimize possible effects of diurnal variation on steroid levels. Animals were stunned with a sharp blow to the head and immediately killed by decapitation. Maternal and pooled fetal blood was obtained immediately after decapitation and then spun to sepa- 
rate the plasma, which was then frozen until analysis could be performed.

Steroid assays. Total corticosterone was measured by a modification of the competitive protein binding assay of Murphy (21), using human plasma as the source of CBG and dextrancoated charcoal to separate free from bound steroid. The interassay variability for the total corticosterone assay was $9 \%$.

The proportion of total corticosterone which was unbound to CBG was determined according to the method of Martin et al. (22). A $100 \mu \mathrm{l}$ plasma sample was incubated with a trace amount of $\mathrm{H}^{3}$-corticosterone and allowed to equilibrate at $37^{\circ} \mathrm{C}$ for 30 min, after which a $25 \mu \mathrm{l}$ aliquot is taken for determination of total radioactivity; the remainder is placed on ice for $30 \mathrm{~min}$, after which non-CBG-bound steroid is removed by treatment with $25 \mu$ l of dextran-coated charcoal solution $(3.75 \mathrm{~g}$ of activated charcoal and $0.375 \mathrm{~g}$ of dextran T500 in a $50 \mathrm{mM}$ phosphate solution, $\mathrm{pH}$ 7.4) for $10 \mathrm{~min}$ on ice. The dextran-charcoal-treated plasma is then centrifuged at $3000 \times g$ for 10 min at $4^{\circ} \mathrm{C}$ after which a $50-\mu \mathrm{l}$ aliquot is removed and radioactivity measured by scintillation counting to determine CBG-bound steroid levels. Non-CBG-bound corticosterone concentration is then calculated by multiplying the total counts - CBG-bound counts/total counts by the previously determined total corticosterone concentration. Interassay variability was $9 \%$.

CBG-binding capacity was determined by the method of Martin et al. (22). Briefly, endogenous steroids are removed by incubating with dextran-coated charcoal and warming to $37^{\circ} \mathrm{C}$ for $30 \mathrm{~min}$. Plasma is then diluted $1: 100(\mathrm{v}: \mathrm{v})$ with $50 \mathrm{mM}$ phosphate buffer. Two hundred $\mu \mathrm{l}$ of the diluted plasma containing $1 \times 10^{-7} \mathrm{M} \mathrm{H}^{3}$-corticosterone is then incubated for $90 \mathrm{~min}$ on ice to determine total binding capacity. A similar incubation using $1 \times 10^{-7} \mathrm{M}$ of $\mathrm{H}^{3}$-corticosterone and $1 \times 10^{-5} \mathrm{M}$ of nonradioactive corticosterone as a competitor is performed to determine nonspecific binding. Dextran-coated charcoal is then added, the samples centrifuged, and the radioactivity of the supernatants determined and compared to the radioactivity obtained prior to the addition of the dextran-coated charcoal. The total binding minus the nonspecific binding yields the CBGbinding capacity in $\mathrm{ng} / \mathrm{ml}$. Interassay variability was $14 \%$.

One hundred eighty gestations of varying length were studied (105 control and 75 diabetic). Each day of gestation was studied independently, since steroid determination required termination of pregnancy. Thus, two-tailed Student's $t$ test for independent variables was used to compare diabetic and control groups at the different gestational ages.

$\mathrm{H}^{3}$-corticosterone was purchased from New England Nuclear (Boston, MA). Streptozotocin was received courtesy of Upjohn Company (Kalamazoo, MI). All other chemicals were obtained from Sigma Chemical Corp. (St. Louis, MO).

\section{RESULTS}

Results for total and unbound corticosteroids and CBG-binding capacity in fetal plasma for the final 5 days of gestation are shown in Figure $1 a-c$. In control fetuses, total corticosterone concentration reached a peak on day 20 of gestation, and then declined progressively to term (Fig. $1 a$ ). The unbound corticosteroid, which accounted for only $5-10 \%$ of the total, increased approximately 3 -fold after day 18 , and maintained a level of $20-$ $25 \mathrm{ng} / \mathrm{ml}$ from day 19 through term (Fig. 1b). CBG-binding capacity peaked on day 19 and then decreased steadily until term (Fig. 1c).

The fetuses of the diabetic pregnancies had significantly lower total corticosterone concentration when compared to controls on days 19,21, and 22 (Fig. 1a). The overall shape of the developmental profile, with a peak at day 20 , followed by decreasing corticosterone concentration through term, was the same for both groups of fetuses.

No significant differences in unbound corticosterone concen- tration between the diabetic and control groups were noted between days 18 and 22, although day 19 and 20 values tended to be lower (Fig. 1b). Both groups had significantly lower unbound corticosterone levels on day 18 than later in gestation. There was a greater than 2-fold increase in free:bound ratio over the final days of gestation in both diabetic and control groups.

Fetal CBG binding capacity was significantly lower in the experimental group on all days studied (Fig. 1c). Again, the shape of the developmental profile for CBG was the same in both groups, with a rise followed by a decreasing concentration until term; however, the peak in the diabetic group was on day 20 as opposed to day 19 for the control animals.

Data for maternal samples for the final 9 days of gestation are given in Figure $2 a-c$. Unlike control fetuses, which showed marked gestational changes in all three parameters, there were no consistent day-to-day changes in maternal control sera, with the possible exception of day 14 sera which had somewhat higher CBG capacity and lower unbound steroid than later in gestation. Diabetic mothers had significantly lower total corticosterone concentration when compared to control animals for the final 3 days of gestation, but not prior to that point in time (Fig. 2a). No significant differences in non-CBG-bound corticosterone were noted at any time in gestation between the two groups (Fig. $2 b$ ). However, CBG binding capacity in the diabetic mothers was decreased 2- to 3-fold on all days studied (Fig. 2c).

\section{DISCUSSION}

Endogenous fetal glucocorticoids are thought to play a role in the regulation of fetal pulmonary maturation (7). There is a developmental increase in fetal plasma corticosteroid levels that correlates with increasing lung maturation in lambs (23) and rabbits (24). Umbilical cord blood cortisol levels (25) and amniotic fluid cortisol (26-28) have been found to correlate with indices of lung maturation. Decreased amniotic fluid and cord blood cortisol levels $(28,29)$ have been reported in neonates with respiratory distress syndrome.

Although there is evidence that experimentally induced diabetes can effect the morphology and function of the adrenal cortex (30-32) there have been few studies on the glucocorticoid status of the newborn infant $(9-11)$ or fetus $(12,13,15)$ of the diabetic pregnancy. In the human diabetic pregnancy, Gewolb et al. (13) demonstrated decreased unconjugated cortisol in amniotic fluid in diabetic gestations of greater than $30 \mathrm{wk}$ when compared to age-matched uncomplicated pregnancies. Pschera et al. (14) also found lower amniotic fluid cortisol in diabetics between 31 and $40 \mathrm{wk}$ of gestation, although differences did not reach significant levels. Guleff and Beck (15), in the alloxandiabetic rabbit model, found decreased fetal plasma cortisol concentration and decreased in vitro fetal adrenal cortisol and corticosterone production in 28-day-old rabbit fetuses. No changes in fetal corticosterone concentration or in maternal levels of either steroid were noted. Mulay and Solomon (16) also reported decreased total maternal and fetal corticosterone levels in streptozotocin-diabetic rats between days 19 and 22 of gestation. The difference in fetal levels persisted for up to $6 \mathrm{~h}$ postpartum, but by 12-24 h after birth there were no significant differences between newborn rats born to diabetic and control mothers.

In the present study, the total plasma corticosterone in the fetus of the streptozotocin-diabetic rat was significantly decreased when compared to control values during the final days of gestation, consistent with the results of recent animal studies $(15,16)$. This decrease in total plasma corticoids was accompanied by a similar striking reduction in fetal plasma CBG-binding capacity in the experimental group. However, there were no significant differences from control values for unbound plasma corticosterone.

Our data on fetuses from control rat pregnancies are consistent 

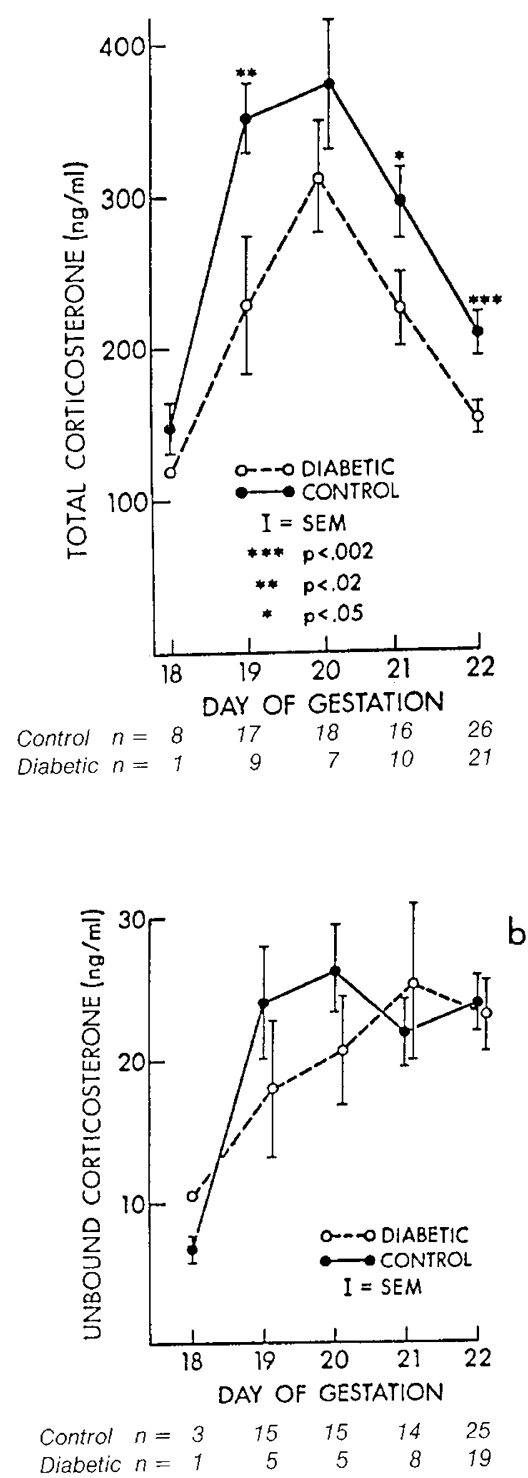

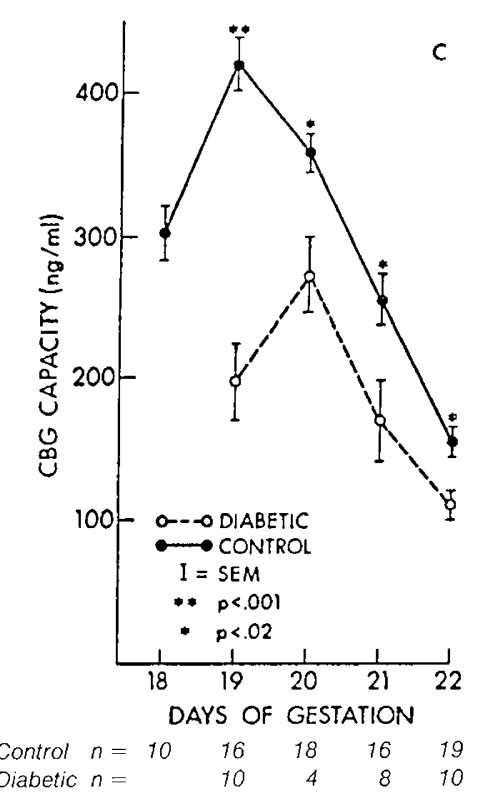

$b$

Fig. 1. $a$, total plasma corticosterone concentration in fetuses of control and diabetic gestations. $b$, unbound plasma corticosterone in fetuses of control and diabetic gestations. $c, C B G$-binding capacity in plasma from fetuses of control and diabetic gestations. Each point represents the mean \pm SEM of a serics of experiments terminated on the indicated day of gestation. $n=$ the number of experiments studied for that day of gestation. Blood from four to eight fetuses from each pregnancy (depending on gestational age) was pooled; thus each pooled litter was considered a single experiment. All results are expressed in $\mathrm{ng} / \mathrm{ml}$. A single two-tailed Student's $t$ test for independent variables was used to compare control and experimental conditions for each day of gestation.

with and the values similar to the results obtained by previous investigators studying normal rat gestation, who describe decreasing total corticosteroid concentration $(16,22,33-35)$, CBGbinding capacity $(22,36)$, and increasing free fraction $(22,35)$ late in gestation. Martin et al. (22) reported a decrease in total fetal corticosteroid from a peak of $449 \mathrm{ng} / \mathrm{ml} 3$ days prior to parturition to $77 \mathrm{ng} / \mathrm{ml}$ at birth, accompanied by a decrease in CBG from a peak of approximately $500 \mathrm{ng} / \mathrm{ml} 4$ days prior to birth to about $100 \mathrm{ng} / \mathrm{ml}$ at term. Unbound steroid levels rose during this period in normal fetuses from approximately 15 to about $60 \mathrm{ng} / \mathrm{ml}$ (22). Mulay and Solomon (16) also described a decrease in fetal rat corticosterone concentration from approximately $1.1 \mathrm{mM} /$ liter on day 19 to about $0.6 \mathrm{mM} /$ liter at term. They did not measure CBG or the non-CBG-bound fraction. Cohen and Guillon (35) recently measured fetal corticosterone late in gestation: total corticosterone decreased from a peak of approximately 275 to about $125 \mathrm{ng} / \mathrm{ml}$ at term, while unbound corticosterone, measured by equilibrium dialysis, rose from 1 to $10 \mathrm{ng} / \mathrm{ml}$ at term.

Martin et al. (22) and others $(36,37)$ also found maternal levels of corticosterone to be relatively unchanged late in gestation in the rat with values ranging from $400-600 \mathrm{ng} / \mathrm{ml}$, a level consistent with our data. Mulay and Solomon (16) and Dupuoy et al. (34) noted a rise in maternal corticosterone levels 3-4 days prior to term, but after that time they found that maternal corticosterone levels remained the same. Relatively constant maternal CBG levels were also found by Martin et al. (22) although their absolute values $(200-400 \mathrm{ng} / \mathrm{ml}$ ) are lower than our data for maternal CBG and much lower than their maternal total corticosterone values. In contrast, Van Baelen et al. (38) noted a slight decrease in maternal CBG levels late in gestation. Thus, although corticosterone crosses the rat placenta in both directions (34), the marked developmental changes in the fetal plasma, contrasted with relatively unchanging maternal pararn- 

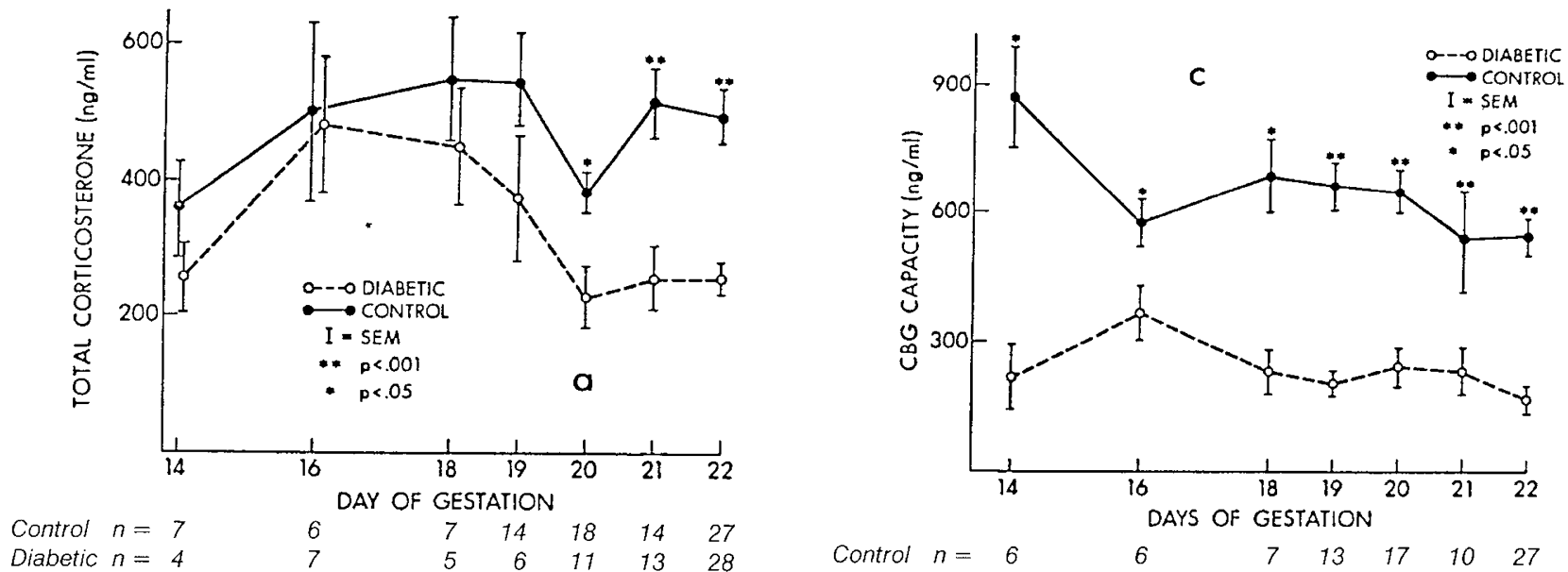

Control $n=\begin{array}{lllllll}6 & 6 & 7 & 13 & 17 & 10 & 27\end{array}$

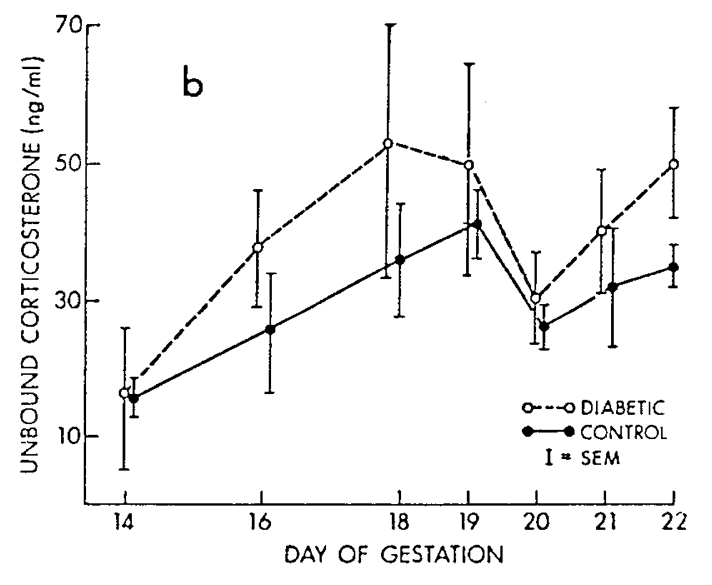

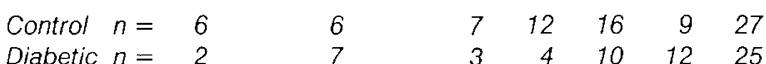

Fig. 2. a, total plasma corticosterone concentration late in pregnancy in control and diabetic rats. $b$, unbound plasma corticosterone concentration late in pregnancy in control and diabetic rats. $c$, CBG-binding capacity in plasma of control and diabetic rats late in pregnancy. Each point represents the mean \pm SEM of a series of experiments terminated on day indicated. $n=$ the number of pregnancies studied for each day. All results are expressed as $\mathrm{ng} / \mathrm{ml}$. Single two-tailed Student's $t$ test for independent variables was used to compare means.

eters, and the difference between absolute maternal and fetal steroid levels suggest that the fetus has some independence in its ability to regulate its internal steroid milieu.

There are significant interspecies differences in the ontogeny of fetal steroid and steroid binding capacity during development. In the fetal sheep, corticoids rise progressively during gestation with an accelerated increase after 130 days of gestation; unbound steroid levels also increase late in gestation (39). In the fetal pig, total corticosteroid concentration increases 2- to 3 -fold late in gestation, while maternal levels do not change significantly (40). In the fetal rabbit, total cortisol rises significantly late in gestation, followed by a 3 -fold rise in unbound steroid levels $(15,24)$, although corticosterone levels do not change significantly (15). In the baboon fetus, cortisol concentration rises 4-fold (from 4 to $15 \mu \mathrm{g} / \mathrm{dl}$ ) late in gestation, coincident with a decrease in CBGbinding-capacity from approximately 60 to $20 \mu \mathrm{g} / \mathrm{dl}$ at term (41). Similar increases in total fetal cortisol levels late in gestation and a higher percentage of unbound cortisol (approximately 25 versus $8 \%$ in adults) have been documented in human pregnancy $(42$, 43). Despite these interspecies variations, all appear to be characterized by increasing concentration of unbound steroids as term approaches.

The developmental profile of CBG also differs according to the species studied. CBG-binding capacity increases late in gestation in fetal sheep $(39,44)$ and in man $(45-47)$ and parallels increased adrenocortical production and increased unbound steroid levels. In contrast, in the fetal baboon (41), rhesus monkey (48), rat $(22,35)$, and mouse (49), CBG-binding capacity decreases as term approaches, leading to the speculation that in these species, the increased unbound steroid concentrations seen late in gestation may be related to decreased CBG-binding capacity.

We have previously demonstrated a delay in fetal lung maturation by day 21 of the diabetic rat gestation. There was a decrease in whole lung phosphatidylcholine and disaturated phosphatidylcholine concentration in the diabetic group. This was accompanied by concommitant morphologic changes in the fetal lungs consistent with maturational delay (3).

The diabetic rat model used in this study differs from the human situation in a number of important parameters, most notably the lack of consistent fetal macrosomia and fetal hyperinsulinemia; thus, observations on the fetus of the diabetic rat are not necessarily applicable to the human diabetic pregnancy. Moreover, as noted above, the fetal developmental profile of glucocorticoid and CBG-binding capacity appears to be different in the rat fetus, where total corticosteroids and CBG decrease late in gestation, whereas these parameters increase in the 3rd trimester human fetus. Nevertheless, the finding of significantly lower total corticosteroid concentration in fetal plasma late in gestation in the fetus of the diabetic rat (and rabbit) raises the 
possibility that the delay in fetal lung maturation seen in the diabetic pregnancy may be in part influenced by an abnormal steroid milieu. However, since no significant differences in the unbound steroid levels were noted between the diabetic and control groups in our study, the contribution of steroids to the process is less clear.

Binding of glucocorticoids to specific receptors in the lungs appear to be the mechanism whereby steroids exert their effect on development. Mulay and Solomon (16) noted a small increase in the cytoplasmic glucocorticoid receptor concentration in lungs of fetuses born to streptozotocin-diabetic rats. They suggested that this increased receptor concentration may be a compensatory mechanism to overcome the effects of decreased corticosterone concentration in these fetuses. In contrast, Boutwell and Goldman (50) found no difference in cytosolic steroid receptor concentration in streptozotocin-diabetic rat fetuses 1 day prior to term, but did observe decreased nuclear uptake of steroids in the experimental group. More work is needed to clarify the role of lung steroid receptors on lung development in fetuses of diabetic mothers.

The decreased CBG-binding capacity in both maternal and fetal plasma in diabetes may be related to decreased production in the liver or to increased trans-capillary protein loss (51), and thus may not be a specific effect on $\mathrm{CBG}$; this point needs further investigation. The decrease in CBG-binding capacity observed in diabetes may have a compensatory function in the face of decreased adrenocortical production rate, by keeping the amount of free circulating steroid relatively constantly. Similarly, the fact that in normal rat gestation CBG-binding capacity declines parallel to and perhaps just prior to the fall in total corticosterone (Fig. $1 a$ and $c$ ) has led to the speculation that fetal CBG may play a role in controlling maturational processes in the fetal rat by regulating the amount of unbound steroid able to interact with specific organ steroid receptors (7).

At present, the mechanism whereby the diabetic state leads to perturbed adrenocortical functioning is not clear. A direct effect of streptozotocin is unlikely since the majority of a dose of streptozotocin has been shown to be cleared from the rat circulation by $6 \mathrm{~h}(20)$, and mating was not begun in the present series of experiments until at least 5 days had elapsed (and many rats were not successfully impregnated for a number of weeks after injection). It is also unlikely that impairment of glucocorticoid production in the fetus of the streptozotocin-diabetic rat is the result of a direct insulin effect, since these fetuses are not hyperinsulinemic (2). Hyperglycemia may affect the adrenal function, but experimental data are conflicting. Hart et al. (52) noted that consumption of concentrated sugar solutions led to elevations in plasma corticosterone in rats; however, other studies (53) found a decrease in steroid levels. Further work is needed to clarify the reason(s) for the impaired adrenal function observed in some species with diabetes.

Acknowledgments. The authors thank Ms. Myrtle Baudy for assistance in the typing of the manuscript and Mr. William Merdian for expert technical assistance.

\section{REFERENCES}

1. Robert MF, Neff RK, Hubbell JP, Taeusch HW, Avery ME 1976 Association between maternal diabetes and the respiratory distress syndrome in the newborn. N Engl J Med 294:357-360

2. Gewolb IH, Barrett C, Wilson CM, Warshaw JB 1982 Delay in pulmonary glycogen degradation in fetuses of streptozotocin diabetic rats. Pediatr Res 16:869-873

3. Gewolb IH, Rooney SA, Barrett C. Wilson C, Light D, Ingleson L, Gross I, Warshaw JB 1985 Delayed fetal lung development in the fetus of the diabetic rat. Experimental Lung Res 8:141-151

4. Sosenko IRS, Lawson EE, Demottaz V, Frantz ID 1980 Functional delay in lung maturation in fetuses of diabetic rabbits. $J$ Appl Physiol 48:643-647

5. Bose CL, Manne DN, D'Ercole AJ, Lawson EE 1980 Delayed fetal pulmonary maturation in a rabbit model of the diabetic pregnancy. J Clin Invest 66:220226

6. Mulay S, Mc Naughton L 1983 Fetal lung development in streptozotocin- induced experimental diabetes: cytidylyl transferase activity, disaturated phosphatidyl choline and glycogen levels. Life Sci 33:637-644

7. Ballard PL 1982 Hormonal aspects of fetal lung development. In: Farrell PM (ed) Lung Development: Biological and Clinical Perspectives, Vol II. Academic Press, New York, pp 205-253

8. Rooney SA 1983 Biochemical development of the lung. In: Warshaw JB (ed) The Biological Basis of Reproductive and Developmental Medicine. Elsevier Science Publishing Co, New York, pp 239-287

9. Kenny FM, Preeyansombat C, Spaulding JS 1966 Cortisol production rate. IV. Infants born of steroid-treated mothers and of diabetic mothers. Infants with trisomy syndrome and with anencephaly. Pediatrics 37:960-966

10. Migeon CJ, Nicolopoulos D, Cornblath M 1960 Concentrations of 17 -hydroxycorticosteroids in the blood of diabetic mothers and in blood from the umbilical cords of their offspring at the time of delivery. Pediatrics 25:605-611

11. Cathro DM, Forsyth CC 1965 Excretion of corticosteroids by infants of prediabetic mothers. Arch Dis Child 40:251-252

12. Chattoraj SC, Carroll CJ, Turner AK, Gillespie L, Pinkus JL, Charles D 1974 Carbohydrate intolerance: its influence on maternal and fetal levels of cortisol and cortisone. Obstet Gynecol 44:646-656

13. Gewolb IH, Hobbins JC, Tan SY 1977 Amniotic fluid cortisol in high-risk human pregnancies. Obstet Gynecol 49:466-470

14. Pschera H, Bjorkhem I, Carlstrom K, Lantto O, Lunell NO, Persson B, Somell C. Stangenburg M, Wager J 1979 Total cortisol and L/S ratio in amniotic fluid in late pregnancies complicated by diabetes mellitus. Horm Metabol Res 11:612-615

15. Guleff PS, Beck RR 1981 Maternal and fetal adrenocortical function in the diabetic rabbit. Am J Physiol 240:E217-E225

16. Mulay S, Solomon S 1983 Influence of streptozotocin-induced diabetes in pregnant rats on plasma corticosterone and progesterone levels and on cytoplasmic glucocorticoid receptors in fetal tissues. J Endocrinol 96:335345

17. Golob EK, Rishi S, Becker KL, Moore C, Shah N 1970 Effect of streptozotocininduced diabetes mellitus on pancreatic insulin content of the fetus. Diabetes 19:610-613

18. Eriksson V, Andersson A, Effendic, Elde S, Hellerstrom C 1980 Effects on the foetal and newborn rat with respect to birth weight, insulin concentration. and pancreatic contents of insulin, glycogen, and somatostatin. Acta Endocrinol 94:354-364

19. Pitkin RM, Van Orden DE 1974 Fetal effects of maternal streptozotocin diabetes. Endocrinology 94:1247-1253

20. Karunanayake EH, Hearse DJ, Mellows G 1976 Streptozotocin: its excretion and metabolism in the rat. Diabetologia 12:483-488

21. Murphy BEP 1967 Some studies of the protein-binding of steroids and their application to the routine micro and ultramicro measurement of various steroids in body fluids by competitive protein-binding radioassay. $\mathrm{J}$ Clin Endocrinol Metab 27:973-990

22. Martin CE, Cake MH, Hartmann PE, Cook IF 1977 Relationship between foetal corticosteroids, maternal progesterone and parturition in the rat. Acta Endocrinol 84:167-176

23. Kitterman JA, Liggins GC, Campos GA, Clements JA, Forster CS, Creasy RK 1981 Prepartum maturation of the lung in fetal sheep: relation to cortisol. $\mathrm{J}$ Appl Physiol 51:384-390

24. Mulay S, Giannopoulos G, Solomon S 1973 Corticosteroid levels in the mother and fetus of the rabbit during gestation. Endocrinology 93:1342-1348

25. Murphy BEP 1974 Cortisol and cortisone levels in the cord blood at delivery of infants with respiratory distress syndrome. Am J Obstet Gynecol 119:1112-1120

26. Murphy BEP, Patrick J, Denton RL 1975 Cortisol in amniotic fluid during human gestation. J Clin Endocrinol Metab 40:163-167

27. Tan SY, Gewolb IH, Hobbin JC 1976 Unconjugated cortisol in human amniotic fluid. J Clin Endocrinol Metabl 43:412-418

28. Fencl M, Tulchinsky D 1975 Total cortisol in amniotic fluid and fetal lung maturation. N Engl J Med 292:133-136

29. Murphy, BEP 1974 Evidence of cortisol deficiency at birth in infants with respiratory distress syndrome. J Clin Endocrinol Metabol 38:158

30. De Nicola AF, Fridman O, Del Castillo EJ, Foglia VG 1976 The influence of steptozotocin diabetes on adrenal function in male rats. Horm Metab Res 8:388-392

31. lams SG, Wexler BC 1977 Alloxan diabetes in spontaneously hypertensive rats: gravimetric, metabolic, and histopathological alterations. $\mathrm{Br} \mathrm{J}$ Pathol 58:177-179

32. Wexler BC, Lutmer RF 1975 Adrenal glandular lipids and circulating corticosterone in severely diabetic rats. Br J Exp Pathol 56:299-306

33. Holt PG, Oliver IT 1968 Plasma corticosterone concentrations in the perinatal rat. Biochem J 108:339-341

34. Dupuoy, JP, Coffigny H, Magre S 1975 Maternal and foetal corticosterone levels during late pregniancy in rats. J Endocrinol 65:347-352

35. Cohen A Guilion Y 1985 Effect of fetal decapitation on unbound rat plasma corticosterone concentration at the end of pregnancy. Biol Neonate 47:163169

36. Kuhn NJ 1969 Progesterone withdrawal as the lactogenic trigger in the rat. J Endocrinol 44:39-54

37. Petropoulos EA, Lau C 1973 Fetoplacental contribution to the maternal corticosteroid pool in Long-Evans rats. $J$ Endocrinol 59:183-184

38. Van Baelen H, Vandoren G, De Moor P 1977 Concentration of transcortin in the pregnant rat and its foetuses. J Endocrinol 75:427-431 
39. Ballard PL, Kitterman JA, Bland RD, Clyman RI, Gluckman PU, Platzker ACG, Kaplan SL, Grumbach MM 1982 Ontogeny and regulation of corticosteroid binding globulin capacity in plasma of fetal and newborn lambs. Endocrinol 110:359-366

40. Randall GCB 1983 Changes in the concentrations of corticosteroids in the blood of fetal pigs and their dams during late gestation and labor. Biol Reprod 29:1077-1084

41. Oakey RE 1975 Serum cortisol binding capacity and cortisol concentration in the pregnant baboon and its fetus during gestation. Endocrinology 97:10241029

42. Ballard PL, Granberg P, Ballard RA 1975 Glucocorticoid levels in maternal and cord serum after prenatal betamethasone therapy to prevent respiratory distress syndrome. J Clin Invest 56:1548-1554

43. Sandberg AA, Slaunwhite WR 1959 Transcortin: A corticosteroid binding posterm of plasma II. Levels in various conditions and the effects of estrogens. J Clin Invest 38:1290-1297

44. Fairclough RJ, Liggins GC 1975 Protein binding of plasma cortisol in the foetal lamb near term. J Endocrinol 67:333-341

45. Stahl F, Amendt P. Dorner G 1979 Total and free cortisol plasma levels in pre- and postnatal life. Endokrinologie 74:243-246

46. Aarskog D 1965 Determination of protein-bound and diffusible cortisol in cord plasma from newborn infants, and plasma from their mothers at time of delivery. Acta Paediatr Scand [Suppl] 158:17-36

47. Hau J, Westergaard JG, Teisner B, Svendson P, Grudzinkas JG 1983 Quantification of corticosteroid binding globulin by electroimmunoassay during human pregnancy. Arch Gynecol 233:217-223

48. Beamer N, Hagemenas FC, Kittinger GW 1973 Development of cortisol binding in the Rhesus monkey. Endocrinology 93:363-368

49. Savu L, Nunez E, Jayle MF 1977 Corticosterone binding by mouse sera during foetal and post-natal development. Acta Endocrinol 84:177-190

50. Boutwell WC, Goldman AS 1979 Depressed biochemical lung maturation and steroid uptake in an animal model of infant of diabetic mother. Pediatr Res 13:355(abstr)

51. Rossing N, Parving HH, Lassen NA 1976 Albumin transcapillary escape rate as an approach to microvascular physiology in health and disease. In: Bianchi R, Mariani G, Mc Farlane AS (eds) Plasma Protein Turnover. University Park Press, Baltimore, pp 357-370

52. Hart RP, Coover GD, Shnerson A, Smotherman WP 1980 Plasma corticosterone elevations in rats in response to consumption of concentrated sugar solutions. J Comp Physiol Psychol 94:337-345

53. Levine S, Coover GD 1976 Environmental control of suppression of the pituitary-adrenal system. Physiol Behav 17:35-37

\section{Erratum}

It has come to our attention that the blood lactate concentrations published in the article "Effects of Acidosis on Fetal and Maternal Blood Coagulation: A Fetal Lamb Model" by Kisker CT, Bohlken DP, Clarke WR Pediatr Res 19:78-82, 1985, were in error due to a defect in the kit used for measuring the levels. Additional samples were available and the levels in the animals were remeasured.

Although there is no change in the statistical outcome of the results, line 8 on page 79 should read "an increase in the blood lactate level from $17-177 \mathrm{mg} / \mathrm{dl}$." In Table 1 lactate levels should read as follows:

Table 1. Results of in vivo exposure to lactic acid (mean $\pm S D$ )

\begin{tabular}{|c|c|c|c|c|c|c|c|c|}
\hline & \multicolumn{4}{|c|}{ Fetus } & \multicolumn{4}{|c|}{ Ewe } \\
\hline & \multicolumn{2}{|c|}{$\begin{array}{l}\text { Acidotic } \\
(n=10)\end{array}$} & \multicolumn{2}{|c|}{$\begin{array}{l}\text { Control } \\
(n=8)\end{array}$} & \multicolumn{2}{|c|}{$\begin{array}{l}\text { Acidotic } \\
(n=10)\end{array}$} & \multicolumn{2}{|c|}{$\begin{array}{l}\text { Control } \\
(n=8)\end{array}$} \\
\hline & Pre & Post & Pre & Post & Pre & Post & Pre & Post \\
\hline $\begin{array}{l}\text { Lactate } \\
(\mathrm{mg} / \mathrm{dl})\end{array}$ & $\begin{array}{c}16 \\
( \pm 11)\end{array}$ & $\begin{array}{c}177 \\
( \pm 37)\end{array}$ & $\begin{array}{c}27 \\
( \pm 27) \\
\end{array}$ & $\begin{array}{r}36 \\
( \pm 32) \\
\end{array}$ & $\begin{array}{r}7.2 \\
( \pm 3.6)\end{array}$ & $\begin{array}{c}4.1 \\
( \pm 1.5)\end{array}$ & $\begin{array}{c}6.0 \\
( \pm 1.7)\end{array}$ & $\begin{array}{r}5.3 \\
( \pm 4.0)\end{array}$ \\
\hline
\end{tabular}

